\title{
Use of mesenchymal stem cells seeded on the scaffold in articular cartilage repair
}

\author{
Kaoru Yamagata, Shingo Nakayamada and Yoshiya Tanaka*
}

\begin{abstract}
Articular cartilage has poor capacity for repair. Once damaged, they degenerate, causing functional impairment of joints. Allogeneic cartilage transplantation has been performed for functional recovery of articular cartilage. However, there is only a limited amount of articular cartilage available for transplantation. Mesenchymal stem cells (MSCs) could be potentially suitable for local implantation. MSCs can differentiate into chondrocytes. Several studies have demonstrated the therapeutic potential of MSCs in the repair of articular cartilage in animal models of articular cartilage damage and in patients with damaged articular cartilage. To boost post-implantation MSC differentiation into chondrocytes, the alternative delivery methods by scaffolds, using hyaluronic acid (HA) or poly-lactic-co-glycolic-acid (PLGA), have developed. In this review, we report recent data on the repair of articular cartilage and discuss future developments.
\end{abstract}

Keywords: Articular cartilage, Mesenchymal stem cells (MSCS), Scaffold, Poly-lactic-co-glycolic acids (PLGA), Hyaluronic acid $(\mathrm{HA})$

\section{Background}

The articular cartilage plays an important role in the smooth motion of joints. Aging is associated with thinning of the articular cartilage tissue and reduction of its function. Aging is also associated with diminished physical activity, leading to impaired activity of daily living (ADL) and quality of life (QOL). The articular cartilage is a structurally unique tissue, lacking blood vessels and nerves, and is considered to be in a low-nutrient, low-oxygen environment. Furthermore, the inflammatory milieu breaks down the cartilage matrix and induces apoptosis of chondrocytes, leading to irreversible defect in the cartilage, a process that is currently difficult to repair in patients with cartilage degenerative diseases, including rheumatoid arthritis (RA) and osteoarthritis (OA). While certain managements are available to alleviate pain or recover cartilage function, these do not result in recovery once the articular cartilage is damaged. Thus, there is a need to design new techniques for repair of articular cartilage and hence to improve $\mathrm{ADL}$ and QOL. In fact, several procedures, such as joint replacement, allogeneic chondrocyte implantation, and implantation of mesenchymal stem

\footnotetext{
* Correspondence: tanaka@med.uoeh-u.ac.jp

The First Department of Internal Medicine, School of Medicine, University of Occupational and Environmental Health, Japan, 1-1 Iseigaoka, Yahata-nishi-ku, Kitakyushu 807-8555, Japan
}

cells (MSCs) seeded on scaffold, have been used in regenerative medicine of the articular cartilage.

Joint replacement bears a heavy burden on patients, and some undesirable effects on the surrounding tissues are sometimes unavoidable. Two types of osteochondral transplantations are considered as alternative techniques. One is autologous osteochondral transplantation, which involves grafting articular cartilage taken from healthy subjects into the affected area [1]. The pathological features of the articular cartilage improve over a short term, whereas the long-term effects are inconsistent [1, 2]. The other technique is allogeneic osteochondral transplantation with the goal of repairing widespread defect in the articular cartilage. In fact, this technique provides improvement of the articular cartilage [3]. However, there remain several issues that need to be discussed, such as the need for adaptation of donor's graft size to the recipient one, assessment of the general health condition, with or without infection $[4,5]$.

Autologous chondrocyte implantation has been tried also as an alternative strategy. The aim of such treatment is to repair the articular cartilage via implantation of chondrocytes into the affected area after in vitro proliferation of samples prepared from healthy articular cartilage [6]. It has been reported that chondrocytes seeded on a scaffold then implanted into the cartilaginous 
defect can result in the repair of articular cartilage of the knee and ankle tissues within $7-13$ and $2-5$ years, respectively [7-9]. However, this method has its limitation especially with the use of less than the recommended number of chondrocytes during the implantation process; such cells lose their ability to produce cartilage extracellular matrix (ECM) like hyaline cartilage due to the dedifferentiation of these cells [10-12].

Another promising strategy that has been tested recently is the use of a scaffold alone or bone marrowderived MSCs seeded on scaffold. MSCs reside in many types of tissues, including bone marrow, adipose, or synovium, and are easy to isolate from these organs. In vitro studies showed that bone marrow-derived MSCs can differentiate into various mesenchymal lineages, including chondrocytes [13]. In vivo studies showed that MSCs contribute to the coverage of articular cartilage, indicating that MSCs are proper tool for implantation to repair the articular cartilage [14-16]. Recently, different types of MSCs other than bone marrow-derived MSCs, including ones derived from synovial tissue, peripheral blood, periosteum, or adipose tissue, have been focused in terms of articular cartilage repair [17-20]. The accumulating evidences demonstrate potential utility of MSCs in the repair of articular cartilage. In particular, it is easy to take large amounts of adipose-derived MSCs (ASC) from fat tissue. However, ability to differentiation of ASC into chondrocytes is poor [21, 22].

In this review, we introduce recent evidences and current status based on mechanism of chondrocyte differentiation and regeneration of the articular cartilage, and then discuss future prospects.

Damage of articular cartilage reflects physical disorder in RA $\mathrm{RA}$ is a systemic autoimmune disease characterized by chronic inflammatory synovitis and progressive joint destruction, which is associated with serious morbidity and mortality [23-25]. Without appropriate treatment, the patients suffer heavy physical disorder associated with limited joint function [24, 25]. Especially, destruction of the articular cartilage, but not bone tissue, correlates with the physical disorder of RA [26, 27]. Clinical or structural remission has recently become an achievable goal through the use of methotrexate (MTX) as the first line disease modifying antirheumatic drug, in addition to tumor necrosis factor (TNF) inhibitors, interleukin-6 (IL-6) inhibitors and cytotoxic T-lymphocyte-associated antigen 4 immunoglobulin fusion protein (CTLA-4Ig), or small-molecular compounds that target Janus kinase (JAK) [28-30]. In this regard, rapid and effective induction of remission is a prerequisite for halting the process of joint destruction. However, it is still difficult to repair damaged or degenerated articular cartilage. Therefore, there is a need for novel treatment strategies, such as regenerative medicine.
Mesenchymal stem cells can differentiate into chondrocytes The articular cartilage covering the bone heads is composed of chondrocytes and cartilage ECM, which is comprised of aggrecan, proteoglycan, type II, IX, and XI collagen. These tissues, however, show poor self-repair capability. Damage or loss of these tissues often results in functional disorder such as OA. At present, autologous cartilage tissue implantation is applied for functional recovery of articular cartilage tissue [31], but unfortunately, this treatment has the following demerits. First, only a limited amount of osteochondral tissue can be prepared from the patients. Second, the implantation further hurts the residual healthy articular cartilage. Based on the above fact, there is certainly a need to develop novel therapies that can prevent and promote repair of damaged articular cartilage.

Different scaffolds have been designed as the delivery system for the repair of articular cartilage. MSCs reside in various types of tissues, including bone marrow, adipose, synovium, cartilage tissue, and placenta. These cells can differentiate into different types of cells that constitute the joints, including osteoblasts, osteocytes, tenocytes, adipocytes, and chondrocytes [13]. It is anticipated that the use of MSCs residing on scaffolds may help in the regeneration/repair of degenerated or damaged articular cartilage. However, endogenous MSCs have poor ability to repair articular cartilage. Although MSCs are injected intravenously (IV), intra-articularly (IA), or intra-peritoneally (IP), the cells diffuse into the peripheral blood and reside in nonaffected area [32-35]. Consequently, such implantation has little effect on the phenotype of the destroyed cartilage tissue. In order to overcome this problem, the transplantation of MSC formed in three dimensional structures, such as cell aggregates and sheets, have been tried [36].

On the other hand, other biological functions of MSCs, such as anti-inflammation, anti-fibrosis, migration, and proliferation, have been reported [32, 33, 37, 38], indicating critical role of MSCs instead of chondrocyte differentiation in cell therapies. In this review, we focus on chondrogenesis related to the repair of articular cartilage.

\section{Chondrogenic differentiation between the 2D and 3D cultures}

MSCs in the living body reside in 3dimensional (3D) circumstance. To make implanted MSCs reside in 3D, pre-implantation (IMP) MSCs should be set at 3D, in this case MSCs are seeded on various types of scaffolds. 3D scaffold should be special material, that mimic circumstance in the living body and is proper for cell adhesion, differentiation, proliferation, and formation of cartilage ECM [39].

After harton's jelly (WT)-MSCs were cultured with chondrocyte differentiation medium over 21 days, transcriptional activity of type II collagen gene was increased 
in the culture of 2D (PLGA free monolayer) or 3D with PLGA scaffold [39]. Expression of both type I collagen (an osteoblast marker) and type III collagen (a fibrocartilage marker) were decreased in 3D whereas their expression were increased in 2D. This indicates that MSCs in $3 \mathrm{D}$, but not $2 \mathrm{D}$, may play role in the formation of hyaline cartilage, but not fibrocartilage or bone tissue.

We have reported that MSCs were cultured with cell growth medium in 2D with cell monolayer (PLGA free) or 3D with PLGA plug scaffold [40]. 3D culture at day 7, but not 2D, up-regulated SOX9 (master regulators of bone and cartilage differentiation). MSCs in 3D culture at day 14, but not 2D, showed positive staining for proteoglycan by safranin $\mathrm{O}$ staining. Taken together, 3D-based PLGA promotes efficiently the chondrocyte differentiation of MSCs in vitro without any cytokine stimulation.

Other group showed that compared with 2D culture with MSCs monolayer, collagen-based sponge could enhance differentiation of MSCs into chondrocyte in vitro. This indicates that type II collagen as a cartilage ECM contributes to differentiation of MSCs into chondrocytes.

Thus, these results show significance and generality of 3D MSCs culture with scaffold in chondrogenesis.

\section{PLGA scaffold is required for the repair of articular cartilages}

The purpose of implantation is for MSCs to efficiently differentiate into chondrocytes, then express large amounts of cartilage ECM, form hyaline cartilage, and then assimilate into the surrounding tissues. First, a scaffold is required for MSCs to reside on the damaged articular cartilage. Poly-lactic-co-glycolic acids (PLGA) is representative commonly used scaffold composed of both poly-glycolic acid (PGA) and poly-lactic acid (PLA). PLGA has several advantages, such as controlled biodegradability, i.e. it disintegrate in the living body, low immunogenicity, efficient carrier of drugs to the target tissue, forms a scaffold for regeneration of cartilage defect through the support of cell residence and cell differentiation.

Implantation of PLGA alone into the affected joints of a rabbit model of osteochondral defect results in satisfactory repair of the bone and cartilage tissues and results in adequate cover of the defect with cartilage tissue [41]. This finding indicates that endogenous MSCs can adhere to PLGA, and then help in the repair of articular damage. Another in vitro study showed that MSCs seeded on PLGA can differentiate into chondrocytes without any cytokine stimulation [40]. These data emphasize the utility of PLGA as a MSC scaffold to achieve efficient repair of the articular cartilage. On the other hand, bone marrow-derived MSCs obtained from $I L-1 R a$ gene knockout mice, which mimic various pathological conditions including RA, have low capacity for self-renewal or differentiation into osteoblasts compared to the wild-type mice [42]. It is possible that MSCs from RA patients also have poor capacity for differentiation. Thus, it is preferable perhaps to co-implant normal and exogenous MSCs, but not endogenous MSCs, with a scaffold into the affected area in order to achieve a better repair of the articular cartilage in RA. Another study reported the finding of positive staining for proteoglycan in the affected region and the formation of hyaline cartilage-like tissue after implantation of MSC sheetcoated PLGA+MSCs into the cartilage defect into the smooth white tissue of rabbits [43].

While the scaffold enhances residence of MSCs into the local tissue, this can be augmented by the addition of cytokines. For instance, PLGA with transforming growth factor- $\beta 3$ (TGF- $\beta 3$ ) enhanced MSC differentiation into chondrocytes, while implantation of PLGA with stromal-derived factor-1 $\alpha$ (SDF-1 $\alpha$ ) into resulted in repair of the articular cartilage [44, 45]. Thus, implantation of PLGA combined with various cytokines enhances more efficient differentiation of MSCs into articular cartilage.

MSC implantation is relatively safe. One study reported lack of any oncogenesis or infection at 5-137 months after MSC implantation [46]. On the other hand, implantation of polyglycolic acid-hyaluronan with MSCs also induced repair of the damaged articular cartilage [43]. To date, however, the use of PLGA for the repair of articular cartilage remains experimental. Thus, more efficient tools are needed in the future.

\section{Collagen scaffold provides the repair of articular cartilages}

Collagen molecules are major components of cartilage ECM, and degraded by collagenases in the living body. Collagen-based material provides proper circumstance for chondrocyte differentiation. Thus, the scaffold is commonly applied for repair strategy of articular cartilage.

Li et al. have reported utility of special tool in the repair of articular cartilage [47]. After rabbit MSCs and collagen are capsuled with microsphere, the tool are applied to implantation into affected area of the osteochondral defect of rabbit. This procedure provided positive staining for type II collagen and glycosaminoglycan (CAG), suggesting formation of hyaline-like tissue. Further, implantation of collagen scaffold alone introduces the repair the osteochondral defect [48]. This finding indicates that the scaffold promotes spontaneous differentiation of endogenous MSCs into chondrocytes.

On the other hand, clinical applications have been tried energetically in addition to studies using animal model. Implantation of collagen gel and MSCs into the athlete, who suffers from knee's pain, results in 
the formation of hyaline-like tissue, and functional recovery of the articular cartilage [49]. Collectively, these evidences emphasize that collagen materials are a proper and promising scaffold for the repair of the articular cartilage.

\section{Gelatin scaffold is required for the repair of articular cartilages}

Hydrogel is $3 \mathrm{D}$ polymeric material that can retain large amount of water. The scaffold provides good biocompatibility and can have an affinity with growth factor or cells, such as MSCs. To date hydrogel scaffolds, including agarose or gelatin, have been applied to implantation into the articular cartilage defect with the goal of cartilage repair.

Agarose is polysaccharide composed from the residue of L- and D-galactose. Previously agarose-based 3Dcultures have been performed as a scaffold of MSCs to promote in vitro MSCs chondrogenesis [50]. Implantation of agarose and MSCs into the articular cartilage defect of rabbit resulted in positive staining for type II collagen and proteoglycan, providing the repair of articular cartilage [51]. On the other hand, another group reported the agarose implantation may inhibit spontaneous repair of articular cartilage and further accumulate in the living body due to weak biodegradability. Therefore, this strategy might not been proper for in vivo trial related on the repair of cartilage tissue.

Gelatin is synthesized from denatured collagen, exhibits cell-adhesion and has been be applied in a variety of scaffolds. Thus, gelatin is biodegradable and a promising scaffold for regenerative medicine of articular cartilage.

Ponticiello et al. have reported that human MSCs were seeded on gelatin sponge, and cultured for 21 day, showing type II collagen staining [52]. After that, the MSCs were implanted into the osteochondral defect of rabbits. Gelatin and MSCs were observed to be very biocompatible, with no evidence of immune response or lymphocytic infiltration at the site. Gelatin is a promising candidate as a carrier matrix for MSC-based cartilage regeneration.

On the other hand, gelatin has disadvantage, such as weakness to mechanical stress. Chemical modification of gelatin via cross-linking with visible light improved the weakness to the stress [53]. In fact, implantation of MSCs seeded on cross-linking gelatin into the osteochondral defect of rabbits provides the repair for the affected area [54]. Taken together, gelatin is an appropriate material to repair articular cartilage applied with MSCs.

\section{Other scaffolds that contribute to the repair of articular cartilage}

MSC scaffolds other than PLGA, collagen, or gelatin, such as tricalcium (TCP), PLA, hyaluronic acid (HA), PGA, and fibrin glue, have also been used for implantation into the articular cartilage defect in experimental animal models (Table 1). PLGA is composed of PLA and PGA whilst PGA-hyaluronan is predominantly comprised of PGA and hyaluronan. The both material show biodegradability and help in enhanced residence of MSCs at affected areas. PLGA-based TGF- $\beta 3$-releasing microspheres is used in terms of the following. PLGA is gradually disintegrate in the living body, subsequently result in release of TGF- $\beta 3$ and efficient cytokine effect over the long-term. As a result, implanted MSCs are subjected to chondrocyte differentiation.

Table 1 Application of MSC seeded onto various types of scaffolds into animal models of articular cartilage defect

\begin{tabular}{|c|c|c|c|c|}
\hline Design for Implantation & Animal model & Follow-up period (months) & Finding & Ref. \\
\hline BM-MSC seeded on TCP scaffold & Sheep & 6 & Proteoglycan and type $\|$ collagen & {$[66]$} \\
\hline BM-MSC seeded on PLA scaffold & Dog & 1.5 & Coverage of chondral defect & [67] \\
\hline BM-MSC seeded on HA scaffold & Mini-pig & 3 & Coverage of chondral defect & [14] \\
\hline BMDC seeded on HA scaffold & Goat & 6 & $\begin{array}{l}\text { Coverage of chondral defect, } \\
\text { proteoglycan and type II collagen }\end{array}$ & [55] \\
\hline BM-MSC seeded on type I collagen scaffold & Sheep & 6 & Hyaline-like cartilage & [15] \\
\hline BMDC seeded on PGA or PLGA scaffold & Sheep & 3 & Hyaline-like cartilage & [16] \\
\hline BM-MSC seeded on type I collagen scaffold & Sheep & 12 & Type II collagen & [68] \\
\hline BM-MSC seeded on HA scaffold & Horse & 12 & No difference in chondral surface & [56] \\
\hline BM-MSC seeded on type II collagen scaffold & Pig & 2 & Hyaline-like cartilage & [69] \\
\hline BM-MSC suspended in fibrin glue & Goat & 6 & Improved cartilage tissue & [70] \\
\hline BM-MSC seeded on PGA-hyaluronan & Rabbit & 1.5 & Hyaline-like cartilage & [71] \\
\hline BM-MSC sheet-encapsulated MSC on PLGA scaffold & Rabbit & 3 & Hyaline-like cartilage & [43] \\
\hline MSC seeded on PLGA-based TGF- $\beta 3$-releasing microspheres & Mice & 1.5 & Hyaline-like cartilage & [72] \\
\hline
\end{tabular}

BM-MSC bone marrow-derived mesenchymal stem cells, TCP tricalcium phosphate, PLA polylactic acid, HA hyaluronic acid, PGA polyglycolic acid, PLGA poly-lactic and co-glycolic acids, TGF- $\beta 3$ transforming growth factor- $\beta 3$ 
HA has been used frequently for implantation of MSCs. Implantation of MSCs-HA into the knee joints of pigs with partial defect in the articular cartilage was followed by efficient covering of the cartilage tissue at 12 weeks followed by the formation of hyaline cartilagelike tissue [14]. However this effect was limited after application of HA alone. Saw et al. [55] reported that the amounts of type II collagen and proteoglycan increased in cartilage defects around the femur tissue after implantation of HA and bone marrow-derived cells (BMDC) in goats. A similar procedure was conducted in pigs. However there was no difference in the repair process of articular cartilage based on MRI imaging between HA and HA + MSC groups at 1 year after implantations [56]. These findings suggest that the efficacy of implantation depends on body size. Further studies to examine changes in cell numbers time of implantation and the implantation tool are required.

Several studies have described the implantation of scaffold and MSCs into affected area in patients with damaged articular cartilage (Table 2). The MRI and arthroscopic findings in patients who had undergone implantation of HA and BMDC with MSCs into the injured joint area showed the formation of new hyaline cartilage-like tissue, which assimilated later into the surrounding tissues within 24 months $[57,58]$. Biopsy specimen from these areas showed dense staining for proteoglycan and type II collagen or faint staining for type I collagen, confirming the repair of articular cartilage observed on the MRI images and that the repaired tissue is hyaline cartilage tissue. However, in some cases the results have been the opposite of what was expected.

Table 2 Application of MSC seeded onto different types of scaffolds into patients with damaged articular cartilage

\begin{tabular}{|c|c|c|c|c|}
\hline Technique & $\begin{array}{l}\mathrm{n} \text {; Sex; Age (years) } \\
\text { (mean } \pm \mathrm{SD})\end{array}$ & Follow-up period (months) & Finding & Ref. \\
\hline BM-MSC in type I collagen gel & $1 ; M(31)$ & 12 & Hyaline-like cartilage & [49] \\
\hline $\begin{array}{l}\text { BM-MSC within type I collagen } \\
\text { gel on a collagen scaffold } \\
\text { seeded on PLA scaffold }\end{array}$ & $3 ; 2 \mathrm{M}, 1 \mathrm{~F}(32-45)$ & 18 & Coverage of chondral defect & [73] \\
\hline $\begin{array}{l}\text { BMDC suspended in collagen } \\
\text { or seeded on HA scaffold }\end{array}$ & $48 ; 27 \mathrm{M}, 21 \mathrm{~F}(28 \pm 9)$ & $24-35$ & $\begin{array}{l}\text { Coverage of chondral defect } \\
\text { and hypertrophic cartilage }\end{array}$ & [57] \\
\hline $\begin{array}{l}\text { BMDC seeded on HA scaffold } \\
\text { supplemented with platelet- } \\
\text { rich fibrin }\end{array}$ & $20 ; 12 \mathrm{M}, 8 \mathrm{~F}(28 \pm 9)$ & $29 \pm 4$ & $\begin{array}{l}\text { Proteoglycan and type } \| \\
\text { collagen }\end{array}$ & [58] \\
\hline $\begin{array}{l}\text { BMDC seeded on HA scaffold } \\
\text { supplemented with platelet- } \\
\text { rich fibrin }\end{array}$ & $81 ; 47 \mathrm{M}, 34 \mathrm{~F}(30 \pm 8)$ & $59 \pm 26$ & Hyaline-like cartilage & [74] \\
\hline $\begin{array}{l}\text { BM-MSC within platelet-rich fi- } \\
\text { brin glue }\end{array}$ & $5 ; 4 \mathrm{M}, 1 \mathrm{~F}(25)$ & 12 & Coverage of chondral defect & [75] \\
\hline $\begin{array}{l}\text { BM-MSC covered by } \\
\text { periosteum }\end{array}$ & $72 ; 38$ M, 34F $(44 \pm 11)$ & 24 & Aggrecan and type II collagen & [76] \\
\hline $\begin{array}{l}\text { BMDC with batroxobin } \\
\text { covered by type } \mid / / I I \text { collagen } \\
\text { matrix }\end{array}$ & $15 ; 10 \mathrm{M}, 5 \mathrm{~F}(48)$ & $24-38$ & Coverage of chondral defect & [77] \\
\hline $\begin{array}{l}\text { BM-MSC seeded on type I } \\
\text { collagen scaffold } \\
\text { supplemented with fibrin glue }\end{array}$ & $2 ; 2 \mathrm{M} \mathrm{(24-25)}$ & $30-31$ & $\begin{array}{l}\text { Partial coverage of chondral } \\
\text { defect }\end{array}$ & [78] \\
\hline $\begin{array}{l}\text { Peripheral blood-derived MSC } \\
\text { with HA }\end{array}$ & $5 ; 1 \mathrm{M}, 4 \mathrm{~F}(39 \pm 11)$ & $10-26$ & $\begin{array}{l}\text { Partial coverage of chondral } \\
\text { defect }\end{array}$ & [79] \\
\hline $\begin{array}{l}\text { BMDC within fibrin glue and } \\
\text { coverage with collagen and } \\
\text { collagen membrane }\end{array}$ & $1 ; M ; 37$ yrs & 24 & $\begin{array}{l}\text { Partial coverage of chondral } \\
\text { defect }\end{array}$ & [80] \\
\hline $\begin{array}{l}\text { BMDC in fibrin glue and } \\
\text { coverage with a PGA + HA } \\
\text { membrane }\end{array}$ & $9 ; 5 \mathrm{M}, 4 \mathrm{~F}(48 \pm 9)$ & $20-24$ & Hyaline-like cartilage & [81] \\
\hline $\begin{array}{l}\text { BMDC in collagen/platelet } \\
\text { paste or seeded on HA or } \\
\text { seeded on HA scaffold } \\
\text { supplemented with platelet } \\
\text { gel }\end{array}$ & $49 ; 27 \mathrm{M}, 22 \mathrm{~F}(28 \pm 9)$ & 48 & $\begin{array}{l}\text { Coverage of chondral defect in } \\
45 \%\end{array}$ & [59] \\
\hline $\begin{array}{l}\text { Peripheral blood-derived MSC } \\
\text { and HA }\end{array}$ & $49 ; 17 \mathrm{M}, 32 \mathrm{~F}(37 \pm 7)$ & 24 & $\begin{array}{l}\text { Partial coverage of chondral } \\
\text { defect }\end{array}$ & [18] \\
\hline
\end{tabular}


For example, implantation of HA-BMDC-MSCs into the talus was later found to result in the formation of irregular cartilage-like tissue by MRI with little or no assimilation with the residual articular cartilage [59]. Further instrument for implantation is required for the repair of articular cartilage in the affected region.

\section{Optimization of MSC implantation tool required for the repair of articular cartilage}

Our in vitro study showed that MSCs seeded on PLGA plug can differentiate into chondrocytes in the growth medium alone, even when MSCs were not cultured in chondrocyte differentiation medium [40]. In order to avoid improper cell differentiation, e.g., osteoblast cells that can trigger ectopic calcification, a special vehicle is needed in advance to direct MSCs into chondrocyte differentiation.

Various mechanisms have been proposed for the differentiation of MSC into chondrocytes. In vitro studies showed that TNF- $\alpha$, IL-1 $\beta$, and IL-17 suppress MSC differentiation into chondrocytes [60-64]. Specifically, TNF- $\alpha$ and IL-1 $\beta$ inhibit the smad signaling pathway, and concomitantly down-regulate Sox9 gene, which encodes master transcriptional factor required for chondrocyte differentiation $[61,62]$. On the other hand, IL-17 inhibits the activity of protein kinase A (PKA), leading to low phosphorylation level of SOX9, which consequently inactivate SOX9 [64]. Taken together, proinflammatory cytokines do not only inflict damage of joints, but also suppress MSC differentiation into chondrocytes. Notably, stimulation of MSCs, which produce high levels of IL-6, with IL-6R results in the activation of IL-6/IL-6R signaling, which in turn induces the expression of various cartilage-related genes in MSCs, resulting in MSC differentiation into chondrocytes [65].

Based on the above information, it is interesting to study whether implantation of PLGA and IL-6R-treated MSCs contributes to the repair of articular cartilage.

\section{Conclusions}

There is a disadvantage in using osteochondral repair as the goal of treatment of articular cartilage tissue damage, since such strategy can negatively affect the residual healthy cartilage tissue. New methods of MSC-based therapy have been tried for the repair of articular cartilage damage. In vitro studies demonstrated that MSCs can differentiate into chondrocytes. Further, 3D culture applied with scaffold enhanced differentiation of MSCs into chondrocytes. In animal models of cartilage damage, the use of local implantation system comprising scaffolds with MSCs, such as PLGA and HA, can result in repair of the articular cartilage with the formation of new hyaline cartilage- like tissue. Furthermore, implantation of MSCs seeded on scaffold into the damaged articular cartilage of patients resulted in histopathological improvement with regeneration of the cartilage tissue. Further studies are necessary to find optimal implantation vehicles that can result in regeneration of articular cartilage.

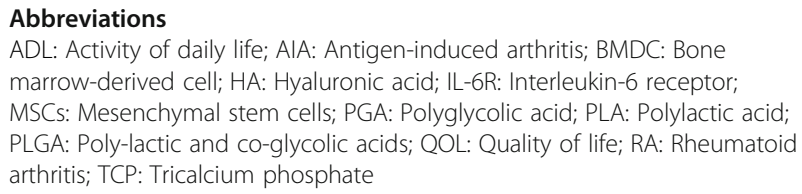

\section{Acknowledgments}

We express our sincere gratitude to all the researchers, collaborators, and technical assistants for contributing to the work cited in this manuscript.

\section{Funding}

This work was supported in part by a Grant-In-Aid for Scientific Research from the Ministry of Health, Labor and Welfare of Japan, the Ministry of Education, Culture, Sports, Science and Technology of Japan, Japan Agency for Medical Research and Development, and the University of Occupational and Environmental Health, Japan, through UOEH Grant for Advanced Research.

Availability of data and materials

Not applicable.

\section{Authors' contributions}

All authors contributed equally to the drafting of the manuscript. All authors read, revised, and approved the final manuscript.

\section{Ethics approval and consent to participate}

Not applicable.

\section{Consent for publication}

Not applicable.

\section{Competing interests}

Y. Tanaka, has received consulting fees, speaking fees, and/or honoraria from Daiichi-Sankyo, Astellas, Pfizer, Mitsubishi-Tanabe, Bristol-Myers, Chugai, YL Biologics, Eli Lilly, Sanofi, Janssen, UCB and has received research grants from MitsubishiTanabe, Takeda, Bristol-Myers, Chugai, Astellas, Abbvie, MSD, Daiichi-Sankyo, Pfizer, Kyowa-Kirin, Eisai, Ono. S. Nakayamada, has received speaking fees from BristolMyers, UCB, Astellas, Abbvie, Eisai, Pfizer, Takeda and has received research grants from Mitsubishi-Tanabe, Novartis and MSD. K. Yamagata declares no conflict of interest.

\section{Publisher's Note}

Springer Nature remains neutral with regard to jurisdictional claims in published maps and institutional affiliations.

Received: 14 December 2017 Accepted: 26 February 2018 Published online: 12 March 2018

\section{References}

1. Solheim E, Hegna J, Oyen J, Harlem T, Strand T. Results at 10 to 14 years after osteochondral autografting (mosaicplasty) in articular cartilage defects in the knee. Knee. 2013;20:287-90.

2. Valderrabano V, Leumann A, Rasch H, Egelhof T, Hintermann B, Pagenstert G. Knee-to-ankle mosaicplasty for the treatment of osteochondral lesions of the ankle joint. Am J Sports Med. 2009;37:105S-11S.

3. Levy YD, Gortz S, Pulido PA, McCauley JC, Bugbee WD. Do fresh osteochondral allografts successfully treat femoral condyle lesions? Clin Orthop Relat Res. 2013;471:231-7.

4. Williams SK, Amiel D, Ball ST, Allen RT, Wong WW, Chen AC, et al. Prolonged storage effects on the articular cartilage of fresh human osteochondral allografts. J Bone Joint Surg Am. 2003;85-A:2111-20. 
5. Malinin TI, Mnaymneh W, Lo HK, Hinkle DK. Cryopreservation of articular cartilage. Ultrastructural observations and long-term results of experimental distal femoral transplantation. Clin Orthop Relat Res. 1994;303:18-32.

6. Peterson L, Vasiliadis HS, Brittberg M, Lindahl A. Autologous chondrocyte implantation: a long-term follow-up. Am J Sports Med. 2010;38:1117-24.

7. Kon E, Filardo G, Berruto M, Benazzo F, Zanon G, Della Villa S, et al. Articular cartilage treatment in high-level male soccer players: a prospective comparative study of arthroscopic second-generation autologous chondrocyte implantation versus microfracture. Am J Sports Med. 2011:39:2549-57.

8. Nam EK, Ferkel RD, Applegate GR. Autologous chondrocyte implantation of the ankle: a 2- to 5-year follow-up. Am J Sports Med. 2009;37:274-84.

9. Anders S, Goetz J, Schubert T, Grifka J, Schaumburger J. Treatment of deep articular talus lesions by matrix associated autologous chondrocyte implantation - results at five years. Int Orthop. 2012;36:2279-85.

10. Harrison PE, Ashton IK, Johnson WE, Turner SL, Richardson JB, Ashton BA. The in vitro growth of human chondrocytes. Cell Tissue Bank. 2000;1:255-60.

11. Mayne R, Vail MS, Mayne PM, Miller EJ. Changes in type of collagen synthesized as clones of chick chondrocytes grow and eventually lose division capacity. Proc Natl Acad Sci U S A. 1976;73:1674-8.

12. Stokes DG, Liu G, Dharmavaram R, Hawkins D, Piera-Velazquez S, Jimenez SA. Regulation of type-II collagen gene expression during human chondrocyte de-differentiation and recovery of chondrocyte-specific phenotype in culture involves Sry-type high-mobility-group box (SOX) transcription factors. Biochem J. 2001;360:461-70.

13. Pittenger MF, Mackay AM, Beck SC, Jaiswal RK, Douglas R, Mosca JD, et al. Multilineage potential of adult human mesenchymal stem cells. Science. 1999;284:143-7.

14. Lee KB, Hui JH, Song IC, Ardany L, Lee EH. Injectable mesenchymal stem cell therapy for large cartilage defects - a porcine model. Stem Cells. 2007; 25:2964-71.

15. Zscharnack M, Hepp P, Richter R, Aigner T, Schulz R, Somerson J, et al. Repair of chronic osteochondral defects using predifferentiated mesenchymal stem cells in an ovine model. Am J Sports Med. 2010;38:1857-69.

16. Wegener B, Schrimpf FM, Bergschmidt P, Pietschmann MF, Utzschneider S, Milz S, et al. Cartilage regeneration by bone marrow cells-seeded scaffolds. J Biomed Mater Res A. 2010;95:735-40.

17. Koga H, Muneta T, Ju YJ, Nagase T, Nimura A, Mochizuki T, et al. Synovial stem cells are regionally specified according to local microenvironments after implantation for cartilage regeneration. Stem Cells. 2007;25:689-96.

18. Saw KY, Anz A, Siew-Yoke Jee C, Merican S, Ching-Soong Ng R, Roohi SA, et al. Articular cartilage regeneration with autologous peripheral blood stem cells versus hyaluronic acid: a randomized controlled trial. Arthroscopy. 2013;29:684-94.

19. Wakitani S, Goto T, Pineda SJ, Young RG, Mansour JM, Caplan Al, et al. Mesenchymal cell-based repair of large, full-thickness defects of articular cartilage. J Bone Joint Surg Am. 1994;76:579-92.

20. Portron S, Merceron C, Gauthier O, Lesoeur J, Sourice S, Masson M, et al. Effects of in vitro low oxygen tension preconditioning of adipose stromal cells on their in vivo chondrogenic potential: application in cartilage tissue repair. PLoS One. 2013;8:e62368.

21. Kisiday JD, Kopesky PW, Evans CH, Grodzinsky AJ, Mcllwraith CW, Frisbie DD. Evaluation of adult equine bone marrow- and adipose-derived progenitor cell chondrogenesis in hydrogel cultures. J Orthopaed Res. 2008;26:322-31.

22. Afizah H, Yang Z, Hui JH, Ouyang HW, Lee EH. A comparison between the chondrogenic potential of human bone marrow stem cells (BMSCs) and adipose-derived stem cells (ADSCs) taken from the same donors. Tissue Eng. 2007;13:659-66

23. Lee DM, Weinblatt ME. Rheumatoid arthritis. Lancet. 2001;358:903-11.

24. Odegard S, Finset A, Kvien TK, Mowinckel P, Uhlig T. Work disability in rheumatoid arthritis is predicted by physical and psychological health status: a 7-year study from the Oslo RA register. Scand J Rheumatol. 2005;34:441-7.

25. Yelin E. Work disability in rheumatic diseases. Curr Opin Rheumatol. 2007;19:91-6.

26. Kvien TK, Uhlig T. Quality of life in rheumatoid arthritis. Scand J Rheumatol. 2005;34:333-41.

27. Baron R, Kneissel M. WNT signaling in bone homeostasis and disease: from human mutations to treatments. Nat Med. 2013;19:179-92.

28. Kubo S, Yamaoka K, Kondo M, Yamagata K, Zhao J, Iwata S, et al. The JAK inhibitor, tofacitinib, reduces the T cell stimulatory capacity of human monocyte-derived dendritic cells. Ann Rheum Dis. 2014;73:2192-8.
29. Singh JA, Saag KG, Bridges SL Jr, Akl EA, Bannuru RR, Sullivan MC, et al. 2015 American College of Rheumatology guideline for the treatment of rheumatoid arthritis. Arthritis Rheumatol. 2016;68:1-26.

30. Smolen JS, Landewé R, Breedveld FC, Buch M, Burmester G, Dougados M, et al. EULAR recommendations for the management of rheumatoid arthritis with synthetic and biological disease-modifying antirheumatic drugs: 2013 update. Ann Rheum Dis. 2014;73:492-509.

31. Roberts S, Menage J, Sandell $\amalg$, Evans EH, Richardson JB. Immunohistochemical study of collagen types I and II and procollagen IIA in human cartilage repair tissue following autologous chondrocyte implantation. Knee. 2009;16:398-404.

32. Zhang X, Yamaoka K, Sonomoto K, Kaneko H, Satake M, Yamamoto Y, et al. Local delivery of mesenchymal stem cells with poly-lactic-co-glycolic acid nano-fiber scaffold suppress arthritis in rats. PLoS One. 2014;9:e114621.

33. Liang J, Li X, Zhang H, Wang D, Feng X, Wang $H$, et al. Allogeneic mesenchymal stem cells transplantation in patients with refractory RA. Clin Rheumatol. 2012;31:157-61.

34. Ra JC, Kang SK, Shin IS, Park HG, Joo SA, Kim JG, et al. Stem cell treatment for patients with autoimmune disease by systemic infusion of cultureexpanded autologous adipose tissue derived mesenchymal stem cells. J Transl Med. 2011:9:181.

35. Gonzalez MA, Gonzalez-Rey E, Rico L, Buscher D, Delgado M. Treatment of experimental arthritis by inducing immune tolerance with human adiposederived mesenchymal stem cells. Arthritis Rheum. 2009;60:1006-19.

36. Tasso R, Augello A, Carida' M, Postiglione F, Tibiletti MG, Bernasconi B, et al. Development of sarcomas in mice implanted with mesenchymal stem cells seeded onto bioscaffolds. Carcinogenesis. 2009;30:150-7.

37. Maria AT, Toupet K, Maumus M, Fonteneau G, Le Quellec A, Jorgensen C, et al. Human adipose mesenchymal stem cells as potent anti-fibrosis therapy for systemic sclerosis. J Autoimmun. 2016;70:31-9.

38. Liu L, Chen JX, Zhang XW, Sun Q, Yang L, Liu A, Hu S, et al. Chemokine receptor 7 overexpression promotes mesenchymal stem cell migration and proliferation via secreting chemokine ligand 12. Sci Rep. 2018;8:204.

39. Paduszyński P, Aleksander-Konert E, Zajdel A, Wilczok A, Jelonek K, Witek A, Dzierżewicz Z, et al. Changes in expression of cartilaginous genes during chondrogenesis of Wharton's jelly mesenchymal stem cells on three-dimensional biodegradable poly(L-lactide-co-glycolide) scaffolds. Cell Mol Biol Lett. 2016;21:14.

40. Sonomoto K, Yamaoka K, Kaneko H, Yamagata K, Sakata K, Zhang X, et al. Spontaneous differentiation of human mesenchymal stem cells on polylactic-co-glycolic acid nano-fiber scaffold. PLoS One. 2016;11:e0153231.

41. Toyokawa N, Fujioka H, Kokubu T, Nagura I, Inui A, Sakata R, et al. Electrospun synthetic polymer scaffold for cartilage repair without cultured cells in an animal model. Arthroscopy. 2010;26:375-83.

42. Mohanty ST, Kottam L, Gambardella A, Nicklin MJ, Coulton L, Hughes D, et al. Alterations in the self-renewal and differentiation ability of bone marrow mesenchymal stem cells in a mouse model of rheumatoid arthritis. Arthritis Res Ther. 2010;12:R149.

43. Qi Y, Du Y, Li W, Dai X, Zhao T, Yan W. Cartilage repair using mesenchymal stem cell (MSC) sheet and MSCs-loaded bilayer PLGA scaffold in a rabbit model. Knee Surg Sports Traumatol Arthrosc. 2014;22:1424-33.

44. Morille M, Van-Thanh T, Garric X, Cayon J, Coudane J, Noël D, et al. New PLGA-P188-PLGA matrix enhances TGF-beta3 release from pharmacologically active microcarriers and promotes chondrogenesis of mesenchymal stem cells. J Control Release. 2013;170:99-110.

45. Yu Y, Brouillette MJ, Seol D, Zheng H, Buckwalter JA, Martin JA. Use of recombinant human stromal cell-derived factor 1 alpha-loaded fibrin/ hyaluronic acid hydrogel networks to achieve functional repair of fullthickness bovine articular cartilage via homing of chondrogenic progenitor cells. Arthritis Rheumatol. 2015;67:1274-85.

46. Wakitani S, Okabe T, Horibe S, Mitsuoka T, Saito M, Koyama T, et al. Safety of autologous bone marrow-derived mesenchymal stem cell transplantation for cartilage repair in 41 patients with 45 joints followed for up to 11 years and 5 months. J Tissue Eng Regen Med. 2011;5:146-50.

47. Li YY, Cheng HW, Cheung KM, Chan D, Chan BP. Mesenchymal stem cellcollagen microspheres for articular cartilage repair: cell density and differentiation status. Acta Biomater. 2014;10:1919-29.

48. Lubiatowski P, Kruczynski J, Gradys A, Trzeciak T, Jaroszewski J. Articular cartilage repair by means of biodegradable scaffolds. Transplant Proc. 2006; 38:320-2. 
49. Kuroda R, Ishida K, Matsumoto T, Akisue T, Fujioka H, Mizuno K, et al. Treatment of a full-thickness articular cartilage defect in the femoral condyle of an athlete with autologous bone-marrow stromal cells. Osteoarthr Cartil. 2007:15:226e231.

50. Awad HA, Wickham MQ, Leddy HA, Gimble JM, Guilak F. Chondrogenic differentiation of adipose-derived adult stem cells in agarose, alginate, and gelatin scaffolds. Biomaterials. 2004;25:3211-22.

51. Diduch DR, Jordan LC, Mierisch CM, Balian G. Marrow stromal cells embedded in alginate for repair of osteochondral defects. Arthroscopy. 2000;16:571-7.

52. Ponticiello MS, Schinagl RM, Kadiyala S, Barry FP. Gelatin-based resorbable sponge as a carrier matrix for human mesenchymal stem cells in cartilage regeneration therapy. J Biomed Mater Res. 2000;52:246-55.

53. Hoch E, Schuh C, Hirth T, Tovar GE, Borchers K. Stiff gelatin hydrogels can be photo-chemically synthesized from low viscous gelatin solutions using molecularly functionalized gelatin with a high degree of methacrylation. J Mater Sci Mater Med. 2012;23:2607-17.

54. Mazaki T, Shiozaki Y, Yamane K, Yoshida A, Nakamura M, Yoshida Y, et al. A novel, visible light-induced, rapidly cross-linkable gelatin scaffold for osteochondral tissue engineering. Sci Rep. 2014;4:4457.

55. Saw KY, Hussin P, Loke SC, Azam M, Chen HC, Tay YG, et al. Articular cartilage regeneration with autologous marrow aspirate and hyaluronic acid: an experimental study in a goat model. Arthroscopy. 2009;25:1391-400.

56. Mcllwraith CW, Frisbie DD, Rodkey WG, Kisiday JD, Werpy NM, Kawcak CE, et al. Evaluation of intra-articular mesenchymal stem cells to augment healing of microfractured chondral defects. Arthroscopy. 2011;27:1552-61.

57. Giannini S, Buda R, Vannini F, Cavallo M, Grigolo B. One-step bone marrowderived cell transplantation in talar osteochondral lesions. Clin Orthop Relat Res. 2009;467:3307-20.

58. Buda R, Vannini F, Cavallo M, Grigolo B, Cenacchi A, Giannini S. Osteochondral lesions of the knee: a new one-step repair technique with bone-marrow-derived cells. J Bone Joint Surg Am. 2010;92:2-11.

59. Giannini S, Buda R, Battaglia M, Cavallo M, Ruffilli A, Ramponi L, et al. Onestep repair in talar osteochondral lesions: 4-year clinical results and t2mapping capability in outcome prediction. Am J Sports Med. 2013;41:511-8.

60. Sitcheran R, Cogswell PC, Baldwin AS Jr. NF-kappaB mediates inhibition of mesenchymal cell differentiation through a posttranscriptional gene silencing mechanism. Genes Dev. 2003;17:2368-73.

61. Baugé C, Legendre F, Leclercq S, Elissalde JM, Pujol JP, Galéra P, et al. Interleukin-1 beta impairment of transforming growth factor beta1 signaling by downregulation of transforming growth factor b receptor type II and upregulation of Smad7 in human articular chondrocytes. Arthritis Rheum. 2007;56:3020-32.

62. Roman-Blas JA, Stokes DG, Jimenez SA. Modulation of TGF-beta signaling by proinflammatory cytokines in articular chondrocytes. Osteoarthr Cartil. 2007;15:1367-77.

63. Baugé C, Attia J, Leclercq S, Pujol JP, Galéra P, Boumédiene K. Interleukin1 beta upregulation of Smad7 via NF-kappaB activation in human chondrocytes. Arthritis Rheum. 2008;58:221-6.

64. Kondo M, Yamaoka K, Sonomoto K, Fukuyo S, Oshita K, Okada Y, et al. IL-17 inhibits chondrogenic differentiation of human mesenchymal stem cells. PLoS One. 2013;8:e79463.

65. Kondo M, Yamaoka K, Sakata K, Sonomoto K, Lin L, Nakano K, et al. Contribution of the Interleukin-6/STAT-3 signaling pathway to Chondrogenic differentiation of human Mesenchymal stem cells. Arthritis Rheumatol. 2015;67:1250-60.

66. Guo X, Wang C, Zhang Y, Xia R, Hu M, Duan C, et al. Repair of large articular cartilage defects with implants of autologous mesenchymal stem cells seeded into beta-tricalcium phosphate in a sheep model. Tissue Eng. 2004;10:1818-29.

67. Wayne JS, McDowell CL, Shields KJ, Tuan RS. In vivo response of polylactic acid-alginate scaffolds and bone marrow-derived cells for cartilage tissue engineering. Tissue Eng. 2005;11:953-63.

68. Marquass B, Schulz R, Hepp P, Zscharnack M, Aigner T, Schmidt S, et al. Matrix-associated implantation of predifferentiated mesenchymal stem cells versus articular chondrocytes: in vivo results of cartilage repair after 1 year. Am J Sports Med. 2011;39:1401-12.

69. Zhang Y, Wang F, Chen J, Ning Z, Yang L. Bone marrow-derived mesenchymal stem cells versus bone marrow nucleated cells in the treatment of chondral defects. Int Orthop. 2012;36:1079-86.

70. Bekkers JE, Tsuchida Al, van Rijen MH, Vonk LA, Dhert WJ, Creemers LB, et al. Single-stage cell-based cartilage regeneration using a combination of chondrons and mesenchymal stromal cells: comparison with microfracture. Am J Sports Med. 2013:41:2158-66.

71. Patrascu JM, Krüger JP, Böss HG, Ketzmar AK, Freymann U, Sittinger M, et al. Polyglycolic acid-hyaluronan scaffolds loaded with bone marrow-derived mesenchymal stem cells show chondrogenic differentiation in vitro and cartilage repair in the rabbit model. J Biomed Mater Res B Appl Biomater. 2013;101:1310-20

72. Morille M, Toupet K, Montero-Menei CN, Jorgensen C, Noël D. PLGA-based microcarriers induce mesenchymal stem cell chondrogenesis and stimulate cartilage repair in osteoarthritis. Biomaterials. 2016;88:60-9.

73. Wakitani S, Nawata M, Tensho K, Okabe T, Machida H, Ohgushi H. Repair of articular cartilage defects in the patello-femoral joint with autologous bone marrow mesenchymal cell transplantation: three case reports involving nine defects in five knees. J Tissue Eng Regen Med. 2007;1:74-9.

74. Giannini S, Buda R, Cavallo M, Ruffilli A, Cenacchi A, Cavallo C, et al. Cartilage repair evolution in post-traumatic osteochondral lesions of the talus: from open field autologous chondrocyte to bone-marrow-derived cells transplantation. Injury. 2010;41:1196-203.

75. Haleem AM, Singergy AA, Sabry D, Atta HM, Rashed LA, Chu CR, et al. The clinical use of human culture-expanded autologous bone marrow mesenchymal stem cells transplanted on platelet-rich fibrin glue in the treatment of articular cartilage defects: a pilot study and preliminary results. Cartilage. 2010;1:253-61.

76. Nejadnik H, Hui JH, Feng Choong EP, Tai BC, Lee EH. Autologous bone marrow-derived mesenchymal stem cells versus autologous chondrocyte implantation: an observational cohort study. Am J Sports Med. 2010;38(6):1110.

77. Gobbi A, Karnatzikos G, Scotti C, Mahajan M, Mazzucco L, Grigolo B. Onestep cartilage repair with bone marrow aspirate concentrated cells and collagen matrix in full-thickness knee cartilage lesions: results at 2-year follow-up. Cartilage. 2011;2:286-99.

78. Kasemkijwattana C, Hongeng S, Kesprayura S, Rungsinaporn V, Chaipinyo K, Chansiri K. Autologous bone marrow mesenchymal stem cells implantation for cartilage defects: two cases report. J Med Assoc Thail. 2011;94:395-400.

79. Saw KY, Anz A, Merican S, Tay YG, Ragavanaidu K, Jee CS, et al. Articular cartilage regeneration with autologous peripheral blood progenitor cells and hyaluronic acid after arthroscopic subchondral drilling: a report of 5 cases with histology. Arthroscopy. 2011;27:493-506.

80. Gigante A, Cecconi S, Calcagno S, Busilacchi A, Enea D. Arthroscopic knee cartilage repair with covered microfracture and bone marrow concentrate. Arthrosc Tech. 2012;1:e175-e80.

81. Enea D, Cecconi S, Calcagno S, Busilacchi A, Manzotti S, Kaps C, et al. Singlestage cartilage repair in the knee with microfracture covered with a resorbable polymer-based matrix and autologous bone marrow concentrate. Knee. 2013;20:562-9.

\section{Submit your next manuscript to BioMed Central and we will help you at every step:}

- We accept pre-submission inquiries

- Our selector tool helps you to find the most relevant journal

- We provide round the clock customer support

- Convenient online submission

- Thorough peer review

- Inclusion in PubMed and all major indexing services

- Maximum visibility for your research

Submit your manuscript at www.biomedcentral.com/submit
Biomed Central 